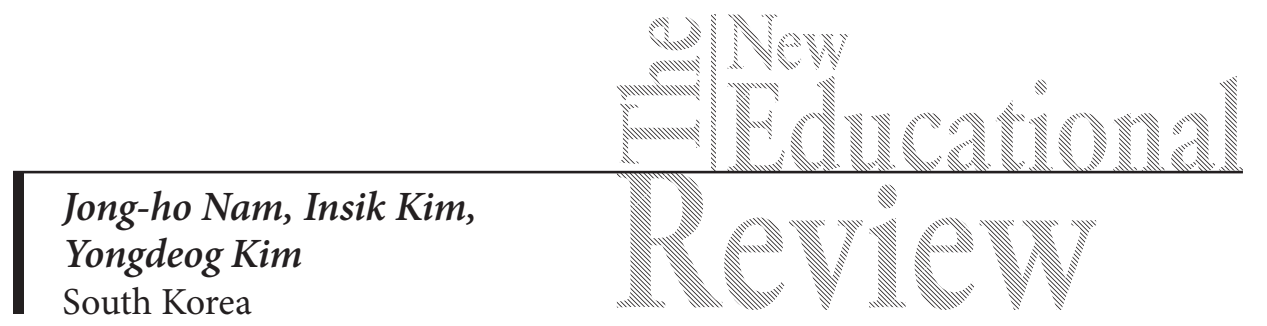

\title{
Social Science Education Offered by Chinese Departments in Korean Universities'
}

DOI: 10.15804/tner.2016.44.2.01

\begin{abstract}
The current curricula of the departments of Chinese in Korea emphasize language and literature, although most students in these departments would prefer an emphasis on curricula in the Chinese social sciences, with less emphasis on language and literature. The research reported here include surveys that identified needs as perceived by students, and contrasted these with studies of existing Korean departments of Chinese. This research indicates that Korean universities currently lack the ability to meet students' needs. For more effective education, Chinese departments should offer two-track curricula, consisting of a language track and a social science track.
\end{abstract}

Keywords: Chinese studies in Korea, Chinese social sciences, Chinese language and literature, two-track curricula

\section{Introduction}

How should we understand China and teach our students? China has become a leading nation in the $21^{\text {st }}$ century. To keep up with the ever-changing China, universities in many countries are revising their courses in each field. This phenomenon is especially obvious in the social sciences, which influence interactions between countries in such areas as Chinese economic policies and diplomatic rela-

1 This study was supported by the Hankuk University of Foreign Studies Research Fund of 2016. 
tions, as well as in conventional education in the Chinese language and literature. Such a trend can be found in Korea as well. Korea is close to China geographically, and it has a cultural background that shares the Confucian heritage and Chinese character culture. Additionally, China and Korea maintain a close economic relationship. Owing to the recent Korea-China FTA, exchanges between the two nations are expected to increase further.

In response to the demand and interest in exchanges between the two nations, universities in Korea are also establishing departments related to China and offering various courses in such areas as the Chinese language, literature, culture, society, politics, and diplomatic relations. However, Chinese education in Korea largely focuses on the Chinese language and literature, so it does not accommodate students' need to acquire general knowledge in Chinese economics, politics, international relations, and society. The present study began with an awareness of this discrepancy. The objective of this study was to investigate how effectively Korean universities are offering knowledge of China that is in line with China's emerging status in the world and also to investigate how they should prepare experts in China.

A review of previous studies can be summarized as follows: Yu (2002) conducted a study comparing linguistic curricula offered by Chinese departments in Chinese and Korean universities and suggested the offer of curricula focusing on the Chinese language for freshmen and sophomore, with curriculum areas with the content of Chinese literature, history, politics, and economics for junior and senior students. Unfortunately, this study compared curricula offered by three universities in Korea and China, respectively, so the sample of the study was too small. It also classified courses in terms of basic linguistic knowledge, linguistic function, and culture. Lee (2005) discussed the current curriculum and suggested improvements in the department of the Chinese language and studies, but he focused on the development of the Key Quality Indicators (KQI) for education, as well as on improvement measures. Park (2004) classified Chinese departments in Korea into six types, such as the Chinese language and literature, Chinese linguistics, and Chinese studies, and then analyzed the curricula of the representative departments. One shortcoming of Park's study was the use of relatively ambiguous categories for analysis, such as Chinese linguistics and the Chinese language. Over the past 10 years, no further research has been conducted on the state of rapidly changing departments and curricula. In addition, Lee (2001) classified Chinese departments into the fields of language, literature, and culture, and further classified them in detail for analysis. Park (2000) analyzed the curricula of Chinese departments in Korea, focusing on linguistics, according to "The Outline of HSK Level Standards 
and Grammatical Level" of the Chinese National Office for Teaching Chinese as a Foreign Language.

Based on the research reviewed here, this study investigates the current curricula of Chinese departments in Korea and suggests what curricula Korean universities should offer. In particular, the study takes an inductive approach, focusing on the social sciences, and uses the two categories of the Chinese language and literature as well as the social sciences, which have never been included in previous studies in order to analyze how well Korean universities are reflecting students' needs in such social science fields as politics, economics, diplomacy, and society, beyond the conventional fields of Chinese linguistics and literature.

Based on an analysis of the current condition in Korean universities, the presented study investigates which field is lacking and analyzes what causes that lack. Then, it suggests a curriculum for Korean universities to effectively teach and study China from the perspective of a foreign country. Specifically, it investigates the following: first, whether students are satisfied with the current curricula, what interests they have and what fields they want to study; and second, the difference between the current curricula of Korean universities and students' needs, and the reason for the difference. Based on the analysis and discussion, this study suggests general improvement measures, such as the curriculum revision of Chinese departments in Korea.

\section{Research Methodology}

The present study first analyzed the current condition of Chinese departments in Korea and conducted a survey using data on Chinese departments, such as curricula, credit hours, full-time teaching faculty, and majors as of 2016. In Korea, there are a total of 113 universities offering 126 Chinese departments (Academy Information Center, http://www.academyinfo.go.kr/). Among the universities, this study analyzed data on related departments at 109 universities that have disclosed information on credit hours and faculty members.

The second phase of the study was a survey offered to 275 students, who were studying in Chinese departments at nine universities in Korea, in order to investigate the students' needs in each Chinese field. The survey was conducted over approximately one month between November 23 and December 19, 2015. A total of 275 questionnaires were retrieved, but 10 questionnaires were excluded from the analysis, because some respondents did not answer all the questions or provided the same answer uniformly. 
In the third phase, academic courses were classified into two broad categories: language and literature vs. social sciences. Language courses (Chinese grammar, conversation, phonetics, phonology, and sociolinguistics) and literature courses (history of literature, literary theory, as well as poetry, novels, essays, etc.) are classified in the language and literature category, while courses with an element of social sciences, such as Chinese current affairs and Chinese trade, are classified in the social science category. Courses in Chinese history and philosophy have strong humanistic characteristics, so they were classified in the language and literature category. Chinese culture courses are also classified in the language and literature category. This classification is based on the following grounds: first, as these are offered as supplementary courses, they are not an independent Chinese culture curriculum but have a supplementary feature designed to help students' acquisition of the Chinese language; second, realistically, most faculty members who are teaching Chinese culture majored in literature. This enables them to offer courses from the perspective of a literature major.

\section{Analysis of Students' Expectations from Chinese Departments}

\section{What kind of education do students want from Chinese departments in Korea?}

Are Korean students satisfied with the current offer of Chinese departments? What fields are they interested in? The study conducted a survey of students majoring in Chinese studies in Korea to find out what areas they are interested in and what revisions they want in the current curricula.

Table 1. Students' interest in each field ( $n=265$, multiple responses allowed)

\begin{tabular}{lccc}
\hline & Language & Literature & Social Science \\
\hline Responses & 203 & 43 & 159 \\
\hline$\%$ & 76.6 & 16.2 & 60.0 \\
\hline
\end{tabular}


Table 2. Preference by school year ( $n=265$, multiple responses allowed)

\begin{tabular}{cccc}
\hline School Year & Language & Literature & Social Science \\
\hline 1 & $81.3 \%$ & $25.0 \%$ & $41.7 \%$ \\
\hline 2 & $55.0 \%$ & $12.5 \%$ & $55.0 \%$ \\
\hline 3 & $69.2 \%$ & $13.8 \%$ & $49.2 \%$ \\
\hline 4 & $74.2 \%$ & $17.7 \%$ & $67.7 \%$ \\
\hline
\end{tabular}

To investigate the students' interests in the field of Chinese studies, the survey asked them in which fields they were interested, from among the Chinese language, literature, and social sciences (multiple responses were allowed). According to the results, the students showed the highest interest in the Chinese language (74.4\%), as expected, followed by social sciences (58.2\%), and literature (15.8\%). That is, the students' interest in the language field was still high, but their interest in social sciences was higher than that in literature.

In terms of the school year, the students' interest in the Chinese language was the highest regardless of their school year, but their interest in social sciences tended to increase gradually depending on their year in university. In particular, the fourth-year students showed the highest interest in social science courses (67.7\%). This result implies that students in their senior year start to realize that their knowledge in social sciences is essential in getting a job in the future.

Table 3. Courses in social sciences should be offered $(n=265)$

\begin{tabular}{lccccc}
\hline & Strongly Agree & Agree & Average & Disagree & Strongly Disagree \\
\hline Responses & 36 & 128 & 87 & 14 & 0 \\
\hline$\%$ & 13.6 & 48.3 & 32.8 & 5.3 & 0 \\
\hline
\end{tabular}

According to the students' responses to the question of whether social science courses should be improved, the percentage of the students who answered "Strongly Agree" (26 respondents, 13.6\%) and "Agree" (128 respondents, 48.3\%) was $61.9 \%$ out of 265 respondents: it was significantly higher compared to the percentage of the students who answered "Average" (87 respondents, 37.8\%) and Disagree (14 respondents, 5.3\%). In particular, out of the 74 students who expressed interest only in the Chinese language, 33 also said that they needed social science courses. Based on the analysis, it can be concluded that the students think that social science courses should be strengthened, regardless of those students' interests. 
Table 4. If social science courses should be offered, what are your reasons? ( $n=241$, multiple responses allowed)

\begin{tabular}{lccccc}
\hline & $\begin{array}{c}\text { For Balanced } \\
\text { Knowledge }\end{array}$ & $\begin{array}{c}\text { For } \\
\text { Employment }\end{array}$ & $\begin{array}{c}\text { Out of Academic } \\
\text { Curiosity }\end{array}$ & $\begin{array}{c}\text { For Common } \\
\text { Sense }\end{array}$ & Other \\
\hline Responses & 147 & 59 & 51 & 18 & 7 \\
\hline$\%$ & 59.8 & 24.0 & 20.7 & 7.3 & 2.8 \\
\hline
\end{tabular}

According to the reasons for strengthening social science courses, the percentage of the students who chose balanced knowledge (59.8\%) and academic curiosity $(20.7 \%)$ was significantly high. This result implies that the students think the current curricula focusing on the Chinese language do not help them understand China in a multi-faceted way. Another interpretation is that the students' interest in China began from the Chinese language and literature but that their interest is expanding to various fields such as Chinese politics, economy, and society. In addition, the ratio of the students who chose practical reasons, such as employment, was high (24\%). This result suggests that the students' need for practical knowledge and capability in politics, economy, and trade is increasing as social and cultural exchanges between Korea and China expand.

Table 5. What should be the ideal ratio between the fields of language and literature and the social sciences? $(n=265)$

\begin{tabular}{lcc}
\hline \multicolumn{1}{c}{ Questions } & $\begin{array}{c}\text { No. of } \\
\text { Respondents }\end{array}$ & $\begin{array}{c}\text { Response } \\
\text { Rate }\end{array}$ \\
\hline $\begin{array}{l}\text { Language and literature courses should be offered. } \\
\text { (The ratio of language and literature courses to social science courses } \\
\text { should be 100:0.) }\end{array}$ & 0.0 \\
\hline $\begin{array}{l}\text { Social science courses should be strengthened based on language } \\
\text { and literature. } \\
\text { (The ratio of language and literature courses to social science courses } \\
\text { should be 75:25.) }\end{array}$ & 92 & 34.7 \\
\hline $\begin{array}{l}\text { Language and literature and social science courses should be offered } \\
\text { equally. } \\
\text { (The ratio of language and literature courses to social science courses } \\
\text { should be 50:50.) }\end{array}$ & & \\
\hline $\begin{array}{l}\text { Social science courses should be strengthened greatly based on } \\
\text { language and literature. } \\
\text { (The ratio of language and literature courses to social science courses } \\
\text { should be 25:75.) }\end{array}$ & & \\
\hline
\end{tabular}




\begin{tabular}{lcc}
\hline \multicolumn{1}{c}{ Questions } & $\begin{array}{c}\text { No. of } \\
\text { Respondents }\end{array}$ & $\begin{array}{c}\text { Response } \\
\text { Rate }\end{array}$ \\
\hline $\begin{array}{l}\text { Language and literature courses should be reduced while concentrat- } \\
\text { ing on social science courses. } \\
\text { (The ratio of language and literature courses to social science courses } \\
\text { should be 0:100.) }\end{array}$ & 2 & 0.0 \\
\hline
\end{tabular}

According to the students' answers on Chinese departments and curricula, the percentage of the students who answered that language and literature courses vs. social science courses should be offered equally was the highest $(52.4 \%)$. That was followed by the ratio of the students who thought social science should be strengthened with a secondary focus on language and literature (34.7\%); and then by the ratio of the students who answered that more social science courses should be offered than language and literature courses (12.0\%). That is, even though the students in Chinese departments still think the Chinese language courses are important, their interest in the social sciences is very high, and they think social science courses should be improved.

Table 6. If the social sciences are strengthened, what courses should be offered?

\begin{tabular}{lccccccc}
\hline \multicolumn{1}{c}{ Field } & Economics & Politics & Diplomacy & Society & $\begin{array}{c}\text { Current } \\
\text { Affairs }\end{array}$ & Law & Trade \\
\hline $\begin{array}{l}\text { No. of } \\
\text { Responses }\end{array}$ & 124 & 58 & 133 & 101 & 123 & 51 & 139 \\
\hline$\%$ & 45.4 & 21.2 & 48.7 & 37.0 & 45.1 & 18.7 & 50.9 \\
\hline
\end{tabular}

The results of the survey showed that the students' needs for courses in Chinese trade and economics were the highest, followed by courses on Chinese diplomacy and current affairs, then Chinese society (37\%), Chinese politics (21\%), and Chinese law (18.7\%).

These survey results are attributable to recent developments in the relationship between Korea and China, particularly the increase in economic exchanges between the two countries. The results also reflect the fact that our society needs human resources with capabilities in social science fields. In particular, as "customized industrial education" is a trend in Korean universities, students think that universities should strengthen related education. The result of this survey reflects the trend quite well. 


\section{The current condition of Chinese departments in Korean universities}

The history of Chinese education in Korea goes back to the establishment of the Department of the Chinese Language and Literature by Seoul National University in 1946, following Korea's liberation from the Japanese occupation. Subsequently, the Hankuk University of Foreign Studies opened the Department of the Chinese Language in 1954, and other universities followed suit. There were only 18 Chinese departments in Korea until the 1970s, but following the establishment of diplomatic relations between Korea and China in 1992, the number of Chinese departments rapidly increased (Park, 2004, 248-249), amounting to 126 Chinese departments as of 2016 (Statistical Yearbook of Education, 2015). This number accounts for $67 \%$ of the 1894 -year universities in Korea. Based on the analysis reported here, the current characteristics of Chinese departments in Korea can be summarized as in Table 7 .

Table 7. Types and ratio of Chinese departments in Korea

\begin{tabular}{llc}
\hline Name of Department & \multicolumn{1}{c}{ Major Department Names } & $\begin{array}{c}\text { Number/ } \\
\text { Percentage } \\
\text { of Schools }\end{array}$ \\
\hline $\begin{array}{l}\text { (China) Department of } \\
\text { Linguistics }\end{array}$ & $\begin{array}{l}\text { Dept. of Chinese, Dept. of Chinese Interpretation } \\
\text { and Translation, Major in Chinese Language }\end{array}$ & $\begin{array}{c}35 \\
(27.8 \%)\end{array}$ \\
\hline $\begin{array}{l}\text { Department of the } \\
\text { Chinese Language and } \\
\text { Literature }\end{array}$ & Dept. of the Chinese Language and Literature & 46 \\
\hline (China) Area Studies & $\begin{array}{l}\text { Dept. of Chinese Studies, Dept. of Chinese Com- } \\
\text { merce, Major in China Studies }\end{array}$ & $(36.5 \%)$ \\
\hline Other & $\begin{array}{l}\text { Dept. of Tourism Chinese Language, Dept. of Chi- } \\
\text { nese and Japanese Studies }\end{array}$ & $\begin{array}{c}39 \\
\end{array}$ \\
\hline & Total & $(4.8 \%)$ \\
\hline
\end{tabular}

Note: Based on data from the Academy Information Center, the Statistical Yearbook of Education, and materials from universities

1. Department of the Chinese Language: The goal of education is to teach Chinese as a foreign language, and courses concentrate on fostering students' linguistic ability. The departments offer a high ratio of language courses and also courses on Chinese history, culture, politics, and economics. However, most of these courses are designed to provide background knowledge to support students' language acquisition. 
2. Department of the Chinese Language and Literature: This is a typical department related to China in Korean universities; its goal is to teach the Chinese language and Chinese literature from the perspective of studies in the humanities.

3. Department of Chinese Area Studies: The purpose of these departments is to provide an overall understanding of China through a regional approach. There are differences among the universities, but these departments offer several Chinese language courses and other courses on Chinese trade and commerce, law, diplomacy, and Chinese economics and politics, to help students acquire an overall knowledge of China. These departments are operated under various names, such as the Department of Chinese Area Studies, the Department of Chinese Business, and the Department of Chinese Studies.

4. Other: Other departments are being operated by integrating departments of Chinese and various academic fields, such as the department of Chinese language tourism or the department of the Chinese and Japanese language.

\section{How well do courses offered by Korean universities reflect the needs of students?}

Then, how well does the current course offer by Chinese departments accommodate students' needs? For an analysis, this study investigated the courses offered by the total of 109 Chinese departments whose information has been disclosed; and obtained the ratio of social science courses out of the total number of courses offered. The result of the analysis showed that the ratio of social science courses offered by Chinese departments was very low.

Table 8. The percentage of Social Science courses out of the total number of courses offered by Chinese departments at major universities in Korea

\begin{tabular}{lc}
\hline Average total credit hours & 118.8 \\
\hline Average credit hours in social science courses & 20.8 \\
\hline The percentage of social science courses out of total credit hours & $17.5 \%$ \\
\hline
\end{tabular}

As can be seen in Table 8, the percentage of Chinese social science courses in Korea is only $17.5 \%$. Compared with students' needs, it is significantly low. 


\section{Results}

Based on the results of this survey, the students' perception of Chinese departments and the situation of current Chinese departments in Korea can be summarized as follows:

First, the biggest need of the students studying in Chinese departments in Korea is learning the Chinese language. This is an essential skill because linguistic ability is a minimum prerequisite to understanding and studying a foreign country.

Second, the students studying in Chinese departments think that more social science courses should be offered. In this study, many students expressed interest in the social sciences and thought that social science course offer should be strengthened.

Third, Chinese departments in Korea can be classified into several types, but regardless of type, all of the Chinese departments include Chinese language courses at some level; they differ depending on which area they emphasize.

Fourth, the reasons for emphasizing Chinese language and literature courses can be summarized as follows:

1. Traditionally, Korea and China have shared the Confucian and Chinese character cultures, so Koreans tend to have a great interest in the Chinese language and literature, particularly in classical Chinese literature;

2. During the Cold War era, Korean research and education in Chinese social sciences were very limited. In particular, during the Korean War, which occurred in 1950, China participated in the war to aid North Korea and became an enemy of South Korea until diplomatic relations between China and Korea were established in 1992. Due to this historical background, conducting research on China, a communist country, was prohibited, and even subscribing to a Chinese newspaper needed government approval. Under these circumstances, Chinese departments in Korea had to focus on the Chinese language and literature, which were not directly related to Chinese politics or ideology; and

3. Korea's first Chinese department was established with a focus on the Chinese language and literature (Seoul National University). This influenced the later establishment of departments as well as the preparation of teaching staff. Consequently, the majority of teaching staff majored in the Chinese language and literature. The shortage of teaching staff in the social sciences may have caused the current shortage of social science courses. 
Table 9. Percentage of social science researchers among teaching staff in Chinese departments in Korea

\begin{tabular}{lc}
\hline Number of professors & 768 \\
\hline Number of the teaching staff who majored in the social sciences & 96 \\
\hline Percentage & $12.5 \%$ \\
\hline
\end{tabular}

Note: Based on the websites of 118 departments that have disclosed information about faculty members.

As shown in Table 9, the number of the teaching staff who majored in the social sciences is only 96 out of the total number of 768 people who are working at 118 universities, as reflected in this study. The small number of the teaching staff in the social sciences can be attributed to the scarcity of social science courses. For such reasons, the courses offered in Chinese departments concentrate on the Chinese language and literature, and the percentage of social science courses is too low to meet students' needs. The students expressed a need to increase the number of social science courses, and they think that an ideal percentage of social science courses is a quarter or a half of the entire number of courses offered. There is a stark discrepancy between the needs of Korean university students and the courses offered.

\section{Conclusion}

Based on the analysis of the current curricula offered by Chinese departments in Korea, as well as the analysis of the current state of teaching staff and the needs of students majoring in Chinese, the following conclusions can be drawn:

First, the students expressed a great interest in the Chinese language, and they thought that the linguistic ability is a prerequisite to studying Chinese literature, politics, economics, and other Chinese areas of study. Therefore, Chinese departments still need to offer Chinese language courses, but from the perspective of a foreign language for better educational effects.

That is, Chinese departments should offer language courses ranging from beginning, to intermediate and advanced courses in five or six steps, depending on students' language aptitude regardless of their major. In particular, by considering various student interests, departments should allow students to choose a major apart from their language ability. In other words, for more effective education, Chinese departments should offer two-track educational curricula, consisting of a language track and a social science track. 
Second, each social science course should be offered on condition that students have mastered basic language skills from the language track. Students who choose the Chinese language as their major can take in-depth language courses, such as theories of linguistics, phonology, and phonetics, beyond simple language education. If students choose Chinese literature, they can take courses on literature theory. Furthermore, students who choose the field of politics, economics, or law can study China in depth by taking both basic and advanced courses in each field, in addition to Chinese language courses. In addition, during their second through fourth year in college, Chinese and social science courses such as Chinese economics or Chinese politics should be offered so that students can study China comprehensively.

Table 10. A suggestion for educational courses

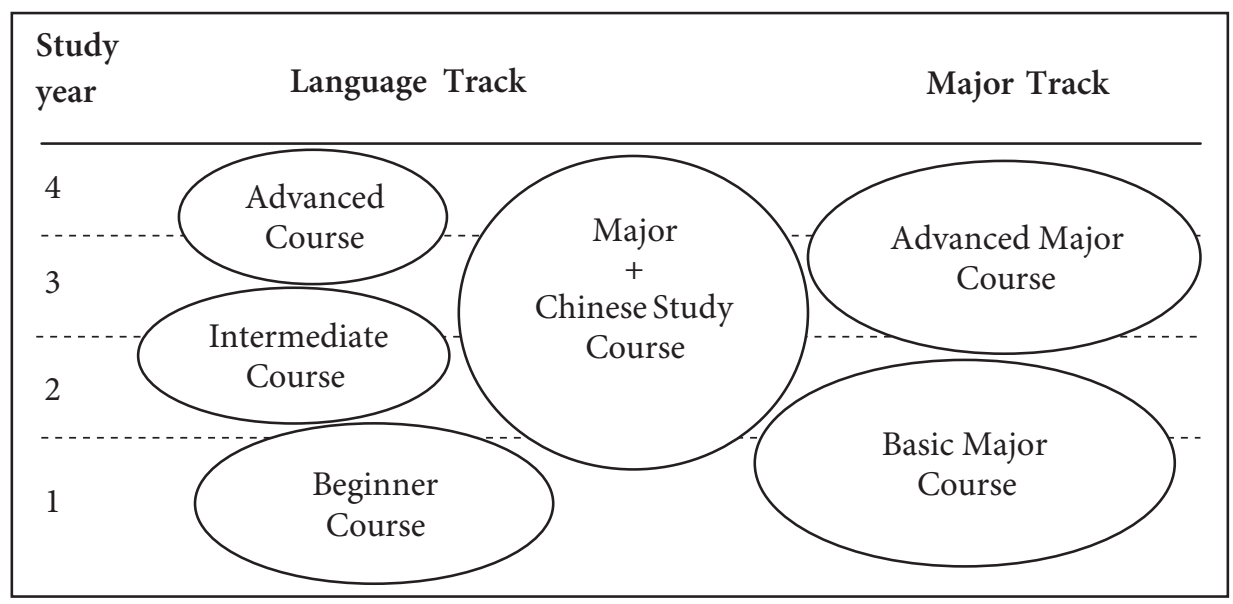

Third, to achieve these goals, Chinese departments need to acquire sufficient teaching staff in the social sciences. As mentioned earlier, this study raised an issue about the shortage of teaching staff who majored in social science fields related to China. To study China through a multi-faceted approach, acquisition of teaching staff in each field of social sciences is very important. 


\section{References}

Korea Ministry of Education - Statistical Yearbook of Education 2015.

Korean Educational Statistics Service (http://kess.kedi.re.kr/).

Korean Council for University Education - Higher Education in Korea (http://www. academyinfo.go.kr/).

Lee, Sang-Do. (2005). The improvement and operation system of the curriculum of Chinese language and studies, Journal of Chinese Studies, 31, 169-201.

Lee, Sang-Hee. (2011). A study on the curriculum of Chinese language major offered by universities in Korea, Master's Thesis, Graduate School of Education at Sookmyung Women's University, Seoul, Korea.

Lee, Yeong-Ho. (2001). A study on the curriculum of Chinese language education, Journal of Chinese Literature, 23.

Jeon, Kwang-jin. (1994). The issues and improvement measures for the current curriculum of Chinese language and literature, Comparative Literature, 1, 223-243.

Park, Duck-jun. (2000). A study on the construction of Chinese language education system at 4-year universities. Journal of Chinese Linguistics in Korea, 11, 1-14.

Park, Heung-soo. (2002). The Improvement Methods of Chinese Language Education through Analysis of an Example, Chinese Literature, 38, 391-401.

Park, Heung-soo. (2004). Types of the Departments of Universities related to Chinese in Korea, Journal of Sinology and China Studies, 33, 247-262.

Yu Qiu Zhen. (2002). The Comparison of the linguistic Curricula between the Chinese Departments of Chinese Universities and of Korean Universities, Studies of Korean \& Chinese Humanities, 9, 364-386. 